\title{
The Inventory Problem with A Non-Symmetric Loss Function
}

\author{
Amaresh Das \& Adnan Omar \\ College of Business \\ Southern University at New Orleans \& \\ New Orleans, LA 70056, USA \\ Tel: 5042865331 E-mail: adas2@cox.net
}

\begin{abstract}
The paper deals with the inventory problem with uncertain demand and a non-symmetric loss function using normal quantile estimation theory The future demand is predicted via Bayesian theory by using data on previous demands. The paper minimizes an inter temporal loss function by choosing 'new' orders. The micro approach of this paper begins by specifying why and how can an inter temporal loss function be minimized and thus explains a richer variation of inventory behavior than an production smoothing model.
\end{abstract}

Keywords: Uncertainty, Quantile estimation, Loss function

\section{Introduction}

The univariate normal quantile estimation theory is applied in many operations research problems. Long ago, Edgeworth applied this technique to determine the amount of cash to be kept on hand in a bank. Suppose that there is a large number of depositors, for each of whom the amount to be withdrawn, during a single given period, is a random variable independent of the withdrawals of the other depositors. Then the total amount withdrawn is a normal random variable $\mathrm{x}$, with mean $\mu$ and variance $\sigma^{2}$, both unknown. The bank may regard as tolerable a certain probability of not being able to meet all withdrawals. The amount of cash $\mathrm{C}$ kept on hand is then $\mathrm{C}=\mu+\delta \sigma$ where $\delta$ is a standard normal deviate corresponding to an upper tail of $\theta$. The purpose of the paper is to build inventory model in conformity with the basic arguments of Edgeworth model. (Note 1). Here the random demand follows a normal distribution. The future demand for the Nth period is related to the previous demand via the parameters. Thus, the future demand is predicted via Bayesian theory by using the data on previous demands. An inter temporal loss function is minimized in the process.

The motivation for the paper comes from the tension that was developing between the emerging macroeconomic and microeconomic views of investors.. Macroeconomics routinely thought of inventories as a destabilizing factor: in theory, the inventory accelerator created cycles that otherwise might not exist; in practice, GNP was more volatile than final sales (GNP less inventory investment). Yet, the prevailing micro theory viewed inventories as a stabilizing factor, something cost minimizing or loss minimizing firm could use instead of aiming at smoothing production.

The production smoothing model which has been the basic paradigm within which empirical research on inventories is being conducted, embeds a host of strong restrictions regarding the nature of demand and market structure. Despite the alleged revolution in inventory practices brought about by computerization, the economy- wide ratio of real inventories to real sales has been trendless for the last 50 years. A more promising avenue, therefore, for improving the performance of models should be to choose an inter temporal loss function and then minimize it by choosing 'new' orders. With that end in view, we will follow Edgeworth's banking model, where future demand will be predicted via Bayesian theory using data on previous demands. (Note 2). The plan of the paper will be as follows: Section I will introduce the problem. Section II will formulate the model. Section II will be followed by section III that will contain an analysis of the determination of the optimum. The paper will conclude with a few remarks in section IV.

\section{The Model}

We will assume that the demand at the beginning of the $i$ th period is : $d_{i}=h_{i}^{\prime} \beta+\varepsilon_{i}$, where $h_{i}$ is a known $q$ component vector, $\beta$ is an unknown q component regression parameter vector, and $\varepsilon_{i}$ is normal with parameters zero and $\sigma$. Further we assume that $U_{i}$ is the quantity to be ordered at the beginning of the $i$ th period and $x_{i}$ is on-hand inventory at the end of the period $i$. Then input to the system is the demand $d_{i}$ and the output is $x_{i}$ which are related by

$$
x_{i}=x_{i-1}+U_{i}-d_{i}=\sum_{j=i} U_{j}-\sum_{j=i} d_{j}+x_{0}
$$


where $\mathrm{x}_{0}$ is a given constant and denoted the stock at the beginning of the first period. The random variables $\mathrm{x}_{\mathrm{i}}$ and $\mathrm{U}_{\mathrm{i}}$ have certain normal distribution. The regression parameter vector $\beta$ is assumed to have a certain prior normal distributions, assuming whether $\sigma$ is known or unknown.

Let $\mathrm{C}_{1}$ be the inventory carrying cost per item per period and $\mathrm{C}_{2}$ be the storage cost per unit per period. Then the specific cost $\mathrm{W}_{\mathrm{i}}$ for the $\mathrm{i}$ th period is

$$
\mathrm{W}_{\mathrm{i}}=\mathrm{C}_{1} \mathrm{x}_{\mathrm{i}}, \quad \mathrm{x}_{\mathrm{i}} \geq 0, \quad \mathrm{~W}_{\mathrm{i}}=-\mathrm{C}_{2} \mathrm{x}_{\mathrm{i}}, \quad \mathrm{x}_{\mathrm{i}}<0
$$

Now we define the quantities

$$
\mathrm{R}_{\mathrm{i}}=\mathrm{E}\left[\mathrm{W}_{\mathrm{i}} \mid \mathrm{x}_{\mathrm{i}-1}, \overline{\mathrm{U}}_{\left.\mathrm{i}-1, \overline{\mathrm{d}}_{\mathrm{i}-1}\right]}\right]
$$

where

$$
\begin{aligned}
& \overline{\mathrm{x}}_{\mathrm{i}-1}=\left(\mathrm{x}_{0}, \mathrm{x}_{1} \ldots \ldots \ldots \ldots \mathrm{x}_{\mathrm{i}-1}\right), \quad \overline{\mathrm{U}}_{\mathrm{i}-1}=\left(\mathrm{U}_{1} \ldots \ldots \ldots . . \mathrm{U}_{\mathrm{i}-1}\right), \overline{\mathrm{d}}_{\mathrm{i}-1}=\left(\mathrm{d}_{1} \ldots \ldots \ldots \mathrm{d}_{\mathrm{i}-1}\right) \text {, and } \\
& M_{i}=E\left(R_{i}\right)=\int_{R_{i} g}\left(\bar{x}_{i-1}, \bar{d}_{i-1}, \bar{U}_{i-1}\right) d \bar{x}_{i-1} d \bar{d}_{i-1} d \bar{U}_{-1}
\end{aligned}
$$

\subsection{Solution}

How to derive the optimum, a question that is ultimately related to minimizing the inter temporal loss function we want to obtain? Now the optimum $U_{i}$ will be determined by minimizing the controller

$$
\mathrm{M}_{\mathrm{i}}+\sum_{\mathrm{j}=\mathrm{i}+1}^{\mathrm{N}} \mathrm{M}_{\mathrm{i}}
$$

where $\mathrm{N}$ is the last period.

We will proceed to show that optimum $\mathrm{U}_{\mathrm{N}}$ will be determined by minimizing the expected value $\mathrm{W}_{\mathrm{N}}$ by using the posterior density of $\mathrm{W}_{\mathrm{N}}$. After determining the optimum $\mathrm{U}_{\mathrm{N}}$, we use this optimum value to find optimum $\mathrm{U}_{\mathrm{N}-1}$ and so on.

We proceed to show a la Gleser and Olkin (1970) that optimum $U_{N}$ will be determined by minimizing the expected values $\mathrm{W}_{\mathrm{N}}$ by using the posterior density of $\mathrm{W}_{\mathrm{N}}$. After determining optimum $\mathrm{U}_{\mathrm{N}}$ we use this optimum value to find optimum $\mathrm{U}_{\mathrm{N}-1}$ and so on.

Optimum $\mathrm{U}_{\mathrm{N}}$ will be obtained by minimizing $\mathrm{M}_{\mathrm{N}}$, where

$$
\begin{aligned}
& \mathrm{M}_{\mathrm{N}}=\left\langle\mathrm{E}\left(\mathrm{W}_{\mathrm{i}} \mid \overline{\mathrm{x}}_{\mathrm{N}-1}, \overline{\mathrm{U}}_{\mathrm{N}-1}, \overline{\mathrm{d}}_{\mathrm{N}-1}\right)\right\} \\
& \left.+\int \mathrm{W}_{\mathrm{N}} \mathrm{g}\left\langle\mathrm{x}_{\mathrm{N}}\right| \overline{\mathrm{x}}_{\mathrm{N}-1}, \overline{\ddot{\mathrm{U}}}_{\mathrm{N}-1}, \overline{\ddot{\mathrm{d}}}_{\mathrm{N}-1}\right) \mathrm{g}\left(\overline{\overline{\mathrm{x}}}_{\mathrm{N}-1}, \overline{\ddot{\mathrm{U}}}_{\mathrm{N}-1}, \overline{\overline{\mathrm{d}}}_{\mathrm{N}-1}\right\} \\
& X \mathrm{dx}_{\mathrm{N}} \mathrm{d} \ddot{\mathrm{x}}_{\mathrm{N}-1} \mathrm{~d} \ddot{\mathrm{U}}_{\mathrm{N}-1} \mathrm{~d} \ddot{\mathrm{d}}_{\mathrm{N}-1}
\end{aligned}
$$

To simplify the analysis, we assume that $\mathrm{x}_{\mathrm{N}}$ depends only on $\mathrm{x}_{\mathrm{N}-1}$ and $\mathrm{U}_{\mathrm{N}}$ and not on the past values of $\overline{\mathrm{x}}_{\mathrm{N}-1}, \overline{\mathrm{U}}_{\mathrm{N}-1}$. Thus, we may write

$$
\begin{aligned}
& \mathrm{g}\left\langle\overline{\mathrm{x}}_{\mathrm{N}} \mid \overline{\mathrm{x}}_{\mathrm{N}-1}, \overline{\mathrm{U}}_{\mathrm{N}-1}, \overline{\mathrm{d}}_{\mathrm{N}-1}\right\rangle \\
& =\int\left\langle\mathrm{g}\left(\mathrm{x}_{\mathrm{N}} \mid \mathrm{x}_{\mathrm{N}-1}, \overline{\ddot{\mathrm{U}}}_{\mathrm{N}}, \overline{\ddot{\mathrm{d}}}_{\mathrm{N}-1}\right) \mathrm{g}\left\langle\mathrm{U}_{\mathrm{N}} \mid \mathrm{x}_{\mathrm{N}-1}, \overline{\ddot{\mathrm{U}}}_{\mathrm{N}-1}, \overline{\mathrm{d}}_{\mathrm{N}-1}\right\rangle \mathrm{dU}_{\mathrm{N}}\right. \\
& \left.\left.=\int \mathrm{g}\left\langle\mathrm{x}_{\mathrm{N}}\right| \mathrm{x}_{\mathrm{N}-1}, \mathrm{U}_{\mathrm{N}}, \overline{\mathrm{d}}_{\mathrm{N}-1}\right) \mathrm{~g}\left\langle\mathrm{U}_{\mathrm{N}}\right| \mathrm{x}_{\mathrm{N}-1}, \overline{\mathrm{U}}_{\mathrm{N}-1}, \overline{\ddot{\mathrm{d}}}_{\mathrm{N}-1}\right\} \mathrm{dU}_{\mathrm{N}} \\
& \left.\left.=\int \mathrm{g}\left\langle\mathrm{x}_{\mathrm{N}}\right| \mathrm{x}_{\mathrm{N}-1}, \mathrm{U}_{\mathrm{N}}, \beta\right) \mathrm{g}\left\langle\beta \mid \overline{\mathrm{d}}_{\mathrm{N}-1}\right\rangle \xi \mathrm{g}\left\langle\mathrm{U}_{\mathrm{N}}\right| \overline{\mathrm{x}}_{\mathrm{N}-1}, \overline{\mathrm{U}}_{\mathrm{N}-1}, \overline{\mathrm{d}}_{\mathrm{N}-1}\right\} \mathrm{dU} \mathrm{N} \mathrm{d} \beta
\end{aligned}
$$

Where $\left.\mathrm{g}\langle\beta| \overline{\mathrm{d}}_{\mathrm{N}-1}\right\}$ is posterior density of $\beta$. This, we have

$$
\begin{gathered}
\left.\left.\left.\mathrm{M}_{\mathrm{N}}=\int \mathrm{w}_{\mathrm{N}} \mathrm{g}\left\langle\mathrm{x}_{\mathrm{N}}\right| \mathrm{x}_{\mathrm{N}-1}, \mathrm{U}_{\mathrm{N}}, \beta\right\} \mathrm{g}\langle\beta| \overline{\mathrm{d}}_{\mathrm{N}-1}\right\} \mathrm{~g}\left\langle\mathrm{U}_{\mathrm{N}}\right| \overline{\mathrm{x}}_{\mathrm{N}-1}, \overline{\mathrm{U}}_{\mathrm{n}-1}, \overline{\mathrm{d}}_{\mathrm{N}-1}\right\} \\
\quad \mathrm{X} \quad \mathrm{g}\left(\overline{\mathrm{x}}_{\mathrm{N}-1}, \overline{\mathrm{U}}_{\mathrm{N}-1}, \overline{\mathrm{d}}_{\mathrm{N}-1}\right) \mathrm{d} \mathrm{U}_{\mathrm{N}} \mathrm{d} \beta \mathrm{d}_{\mathrm{N}-1} \mathrm{~d} \overline{\mathrm{U}}_{\mathrm{N}-1} \mathrm{~d}_{\mathrm{N}-1} \mathrm{dx}_{\mathrm{N}}
\end{gathered}
$$

However, we must have 
$\mathrm{M}_{\mathrm{N}}=\int \mathrm{R}_{\mathrm{N}} \mathrm{g}\left(\overline{\mathrm{x}}_{\mathrm{N}-1}, \overline{\mathrm{U}}_{\mathrm{N}-1}, \overline{\mathrm{d}}_{\mathrm{N}-1}\right) \mathrm{d} \overline{\mathrm{x}}_{\mathrm{N}-1} \mathrm{~d} \overline{\mathrm{U}}_{\mathrm{N}-1} \mathrm{~d} \overline{\mathrm{d}}_{\mathrm{N}-1}$

It follows from (7) and (8) that

$$
\begin{aligned}
\mathrm{R}_{\mathrm{N}} & \left.\left.\left.=\int \mathrm{W}_{\mathrm{N}} \mathrm{g}\left\langle\mathrm{x}_{\mathrm{N}}\right| \mathrm{x}_{\mathrm{N}-1}, \mathrm{U}_{\mathrm{N}}, \beta\right\} \mathrm{g}\langle\beta| \overline{\mathrm{d}}_{\mathrm{N}-1}\right\} \mathrm{~g}\left\langle\mathrm{U}_{\mathrm{N}}\right| \overline{\mathrm{x}}_{\mathrm{N}-1}, \overline{\mathrm{U}}_{\mathrm{N}-1}, \overline{\mathrm{d}}_{\mathrm{N}-1}\right\} \\
\mathrm{X} & \mathrm{dU}_{\mathrm{N}} \mathrm{d} \beta \mathrm{dx}_{\mathrm{N}}
\end{aligned}
$$

Obviously $M_{N}$ is a minimum when $R_{N}$ is a minimum. Now let $\bar{d}_{N-1}=H \beta+\varepsilon$ where $\varepsilon$ is normal with mean vector zero and covariance matrix $\sigma^{2} \mathrm{I}$, and let $\beta$ be normal with mean vector $\beta_{0}$ and covariance matrix $\sigma_{0}^{2} \mathrm{I}$. Then,

$\left.\mathrm{g}\langle\beta| \overline{\mathrm{d}}_{\mathrm{N}-1}\right\}=\mathrm{k} \exp \left\{-\frac{1}{2}\left(\beta-\beta_{1}\right)^{\prime} \sum\left(\beta-\beta_{1}\right)\right)$

Where

$\beta_{1}=\Sigma^{-1}\left(\frac{\mathrm{H}^{\prime} \overline{\mathrm{d}}_{\mathrm{N}-\mathrm{I}}}{\sigma^{2}}+\frac{\beta_{0}}{\sigma_{0}^{2}}\right)$

Where $\sigma^{2}$ and $\sigma_{0}^{2}$ are known. Again, by noting that

$\mathrm{x}_{\mathrm{N}}=\mathrm{x}_{\mathrm{N}-\mathrm{I}}+\mathrm{U}_{\mathrm{N}}-\mathrm{d}_{\mathrm{N}}=\mathrm{x}_{\mathrm{N}-\mathrm{I}}+\mathrm{U}_{\mathrm{N}}-\mathrm{h}_{\mathrm{N}}^{\prime} \beta-\varepsilon_{\mathrm{N}}$

We find that

$$
\mathrm{g}\left\{\left\langle\mathrm{x} \mid \mathrm{x}_{\mathrm{N}-1}\right\rangle, \mathrm{U}_{\mathrm{N}}, \beta\right\}=\mathrm{k} \exp \left\{\frac{1}{2 \sigma^{2}}\left(\mathrm{x}_{\mathrm{N}-\mathrm{I}}+\mathrm{U}_{\mathrm{N}}-\mathrm{h}_{\mathrm{N}}^{\prime} \beta-\mathrm{x}_{\mathrm{N}}\right)^{2}\right\}
$$

Now we define the quantities

$\mathrm{T}=\mathrm{x}_{\mathrm{N}-\mathrm{I}}+\mathrm{U}_{\mathrm{N}}-\mathrm{h}_{\mathrm{N}}^{\prime} \beta_{1} \quad \mathrm{~A}=\left(\mathrm{h}_{\mathrm{N}}^{\prime} \Sigma^{-1} \mathrm{~h}_{\mathrm{N}}+\sigma^{2}\right)^{-1}$

Using (9), (10), and (13). find that

$$
\begin{aligned}
& R_{N}=k \int_{0}^{\infty} C_{1} x_{N} \exp \left\{-\frac{1}{2}\left(x_{N}-T\right)^{2} A\right\} d x_{N}-k \int_{0}^{\infty} C_{2} x_{N} \exp \left\{-\frac{1}{2}\left(x_{N}-T\right)^{2} A\right\} d x_{N} \\
& =\left(C_{1}+C_{2}\right) f(T \sqrt{A})+\left(C_{1}+C_{2}\right) T F(T \sqrt{A})-C_{2} T
\end{aligned}
$$

Where $\mathrm{F}$ and $\mathrm{f}$ are the distribution and density functions at the standard normal variate. Minimizing $\mathrm{R}_{\mathrm{N}}$ with respect to $\mathrm{U}_{\mathrm{N}}$ yields the optimum $\mathrm{U}_{\mathrm{N}}^{*}$ as

$\mathrm{U}_{\mathrm{N}}^{*}=\mathrm{Z}_{\mathrm{p}} \mathrm{A}^{1 / 2}-\mathrm{x}_{\mathrm{N}-\mathrm{I}}+\mathrm{h}_{\mathrm{N}}^{\prime} \beta_{1}$

Where $Z_{p}, p-C_{2} /\left(C_{1}+C_{2}\right)$ is the $p$-th quantile of the standard normal density. Note that $(15)$ relates future $x_{N}$ with respect to $\mathrm{T}$ via the parameters.

To find $U_{N-I}^{*}$, we minimize $M_{N-I}+M_{N}^{*}$ with respect to $U_{N-I}$ where $M_{N}^{*}$ is the value of $M_{N}$ obtained by substituting $\mathrm{U}_{\mathrm{N}}^{*}$ for $\mathrm{U}_{\mathrm{N}}$. Now $\mathrm{M}_{\mathrm{N}}^{*}$ does not contain $\mathrm{x}_{\mathrm{N}-\mathrm{I}}$ and $\mathrm{U}_{\mathrm{N}-\mathrm{I}}$ so that minimum of $\mathrm{M}_{\mathrm{N}-\mathrm{I}}+\mathrm{M}_{\mathrm{N}}^{*}$ is obtained by minimizing $\mathrm{M}_{\mathrm{N}-\mathrm{I}}$ with respect to $\mathrm{U}_{\mathrm{N}-\mathrm{I}}$. This applies to any intermediate stage and we get a regular strategy for finding the optimum controller (Note 3, Note 4). This analysis for the normal error structure model is given by Sarker (1975).

\section{Conclusion}

We connected a single future variable or observation to the past data. This is just a Bayesian theory and we have obtained this Bayesian statistical inventory model over $\mathrm{N}$ discrete periods of equal length within the framework of normal distribution theory. An expression for optimal order quantity at the beginning of the N-th period is obtained. And the expected value of a certain function of this predicted demand is minimized to obtain the required order quantity. However, we may also relate more than a single independent variable to past data and form a more general model and the methodology remains the same. The merit of our work is that during 2000 s economists once again know something they had known in the 1950s: that inventory investment is of the first order importance in business cycles. But, they will be beginning to realize that the standard production smoothing model or the buffer stock model of inventories can be supplanted by a new micro approach. 


\section{References}

Blinder,Alan S. (1986) "Can the Production Smoothing Model of Inventories be saved?" Quarterly Journal of Economics, 101, 431-454

Bray, M. (1981) "Future Trading, rational expectations and the Efficient Market hypothesis," Econometrica, 49, 575-596

Eichenbaum, Martin. (1984). "Rational Expectations and the Smoothing Properties of Inventories of Finished Goods. Journal of Monetary Economics, 14, 71-76.

Gleaser, L. J., and Olkin, I. (1970). "Linear Models in Multivariate Analysis" in Essays in Probability in Statistics, John Wiley \& Sons, Inc,

Grossman, S. J. and Stiglitz, J. S. (1976). "Information and Competitive Price System” American Economic Review,66, , 246-253.

Gutman, I. (1970). Statistical Tolerance regions, Charles Griffith Statistical Monograph, No 26, Charles Griffin, London

Jeffry. M. and Zeldas, S. P. (1987). "Seasonality, Cost Shocks and the Production Smoothing Model of Inventories" Unpublished Manuscript, Department of Economics, University of Pennsylvania.

Markland Johan. (2006). "Controlling Inventories in Divergent Supply Chains with Advance-Order Information", Operations Research, 54, September, 985-1010.

Narragon, E. A., Dessouky. N. I. and Devor. S. E. (1974). "A probabilistic Model for Analyzing Campus Parking Problem" Operations Research, 22, 1025-1039.

Sarker, B. (1975). “A Feedback Inventory Control Systems with Linear Cost” Sankhya, Series B, 37, 241 - 247.

West. K. D. (1987). “The Sources of Fluctuations in aggregate GNP and Inventories”, Unpublished Manuscript, Department of Economics, Princeton University.

Yongwon Sew, Sungwan Jung and Juho Hahm. (2002). “Optimal Research Decision Utilizing Centralized Stock Information in a Two-Echelon Distribution System”, 271, Feb. 2002, 171- 193.

\section{Notes}

Note 1. It is obvious that the problem of inference of normal quintiles of the type of are interesting problems in several situations. The inference problems of the normal quantiles theory associated with classical regression models have been tackled in the literature by various procedures: classical, Bayesian, structural, minimax, etc. For some of the readily available or easily derivable results, see, e.g., Guttman (1970). Narragon et al (1974) applied Edgeworth theory to a campus parking problem where different class of users exhibited varying demand practices.

Note 2.This model differs from the other uncertainty models in the sense that demand is the main source of uncertainty here unlike in the other works, for example, Grossman and Stiglitz (1976) and Bray (1981), where uncertainty is introduced in the form of random supply that prevents price from acting as a price statistic. The major thrust of this model is not to establish conditions under which prices reveal information which can be equivalent to perfect information but to improve the estimate of the parameters determining demand. See on related views

Blinder (1986), Eichenbaum (1984) West (1987), and Jeffry and Zeldes (1987). There are other types of inventory problems specifically related to inventory control where one makes a numerical study using advance order information in supply-chain inventory control, see, for example, see Marklund (2006) and Youngwon, Sungwon and Juho (2002)

Note 3. When $\beta$ and $\sigma$ are both unknown, we have

$$
\left.\mathrm{R}_{\mathrm{N}}=\mathrm{k} \int \mathrm{W}_{\mathrm{N}} \mathrm{g}\langle\beta, \sigma| \overline{\mathrm{d}}_{\mathrm{N}-1}\right) \exp \left(-\frac{1}{2 \sigma^{2}}\left(\mathrm{x}_{\mathrm{N}-1}+\mathrm{U}_{\mathrm{N}}-\mathrm{h}_{\mathrm{N}}^{\prime} \beta-\mathrm{x}_{\mathrm{N}}^{\prime}\right)^{2} \mathrm{dx}{ }_{\mathrm{N}} \mathrm{d} \beta \mathrm{d} \sigma\right.
$$

we assume

$\operatorname{gg}\left\langle\beta, \sigma \mid \overline{\mathrm{d}}_{\mathrm{N}-1}\right\rangle=\mathrm{k} \exp \left\{-\frac{1}{2}(\beta-\beta)^{\prime}\left(\mathrm{H}^{\prime} \mathrm{H}+\mathrm{I}\right)^{-1}\left(\beta-\beta_{1}\right) / \sigma^{2} \quad\right.$ where

$\beta_{1}=\left(\mathrm{H}^{\prime} \mathrm{H}+\mathrm{I}\right)^{-1}\left(\mathrm{H}^{\prime} \overline{\mathrm{d}}_{\mathrm{N}-1}+\beta_{0}\right)$

On integrating (17) with respect to $\beta$ first and then with respect to $\sigma^{-2}$ we have

$$
\begin{aligned}
\mathrm{R}_{\mathrm{N}}= & \mathrm{k} \int \mathrm{C}_{1} \mathrm{x}_{\mathrm{N}}\left[\mathrm{I}+\left(\mathrm{x}_{\mathrm{N}}-\mathrm{T}\right)^{2} / \sigma\right]^{-\left(\mathrm{m}+1^{\prime} 2\right.} \mathrm{dx}_{\mathrm{N}} \\
& -\mathrm{k} \int \mathrm{C}_{2} \mathrm{x}_{\mathrm{N}}\left[\mathrm{I}+\left(\mathrm{x}_{\mathrm{N}}-\mathrm{T}\right)^{2} / \sigma\right]^{-(\mathrm{m}+1) / 2} \mathrm{dx}_{\mathrm{N}}
\end{aligned}
$$


where $\theta=\mathrm{I}+\mathrm{h}_{\mathrm{N}}^{\prime}\left(\mathrm{H}^{\prime} \mathrm{H}+\mathrm{I}\right)^{-1}$. However (20) and (15) have the same form and hence, in this case, we find that

$\mathrm{U}_{\mathrm{N}}^{*}=\mathrm{Z}_{\mathrm{p}} \theta^{\frac{1}{2}}-\mathrm{x}_{\mathrm{N}-\mathrm{I}}+\mathrm{h}_{\mathrm{N}}^{\prime} \beta_{1}$

Where $Z_{p}$ now is the $p$-th quantile of the density

$f(x)=k\left(i+x^{2}\right)^{-(m+1) / 2}$

If $\beta_{1}$ of (19) $\mathrm{s}$ assumed to be known, then (21) is known. Otherwise, we have to use the Bayesian theory for making probability statement about $\mathrm{U}_{\mathrm{N}}^{*}$, after substituting Bayes' estimate for $\theta_{1}$ in (21)

Note 4. Another approach where the parameters are unknown is to use Blackwell- Lehman-Scheffe theorem and obtain $\mathrm{U}^{*}{ }_{\mathrm{N}}$ as the quantile of a certain conditional distribution function. 